\title{
INTEGRATION OF REMOTE SENSING \& ENVIRONMENTAL SCIENCE IN PLACED-BASED LEARNING
}

\author{
A. R. Ignatius*a, M. G. Flood b \\ a Institute for Environmental and Spatial Analysis, University of North Georgia. Oakwood, GA 30566 - amber.ignatius@ung.edu \\ b Department of Biology, University of North Georgia. Oakwood, GA 30566 - margi.flood@ ung.edu
}

KEY WORDS: Remote Sensing, Pedagogy, Google Earth Engine, Environmental Science, Place-Based Education, STEM

\begin{abstract}
:
Integration of remote sensing techniques and Environmental Science methodologies in placed-based curriculum design creates unique learning opportunities. To promote introductory-level student engagement with STEM, our team designed a set of multidisciplinary teaching materials to intensely examine a single location: the Lake Sidney Lanier watershed of North Georgia, USA. Using a combination of scientific approaches from a variety of disciplines, course exercises encourage students to holistically learn about environmental conditions within the watershed. Remote sensing exercises are embedded throughout the course content and include analysis of historic aerial imagery, Landsat-derived dynamic surface water extent, google timelapse land cover change, Sentinel 2 spectral bands, and evaluation of topography.

Fundamental spatial concepts of scale and connectivity are considered using interdisciplinary approaches and local data. Landscape ecology is presented alongside remote sensing concepts of spatial and temporal resolution. This allows students to think about the diverse ways scientists understand scale, pattern, and the definition of "place". Multiple data sources are also provided for each topic. For example, remote sensing imagery is used to investigate surface water conditions during drought and high-rainfall time periods. In addition, USGS streamgage river discharge data and rainfall estimates are provided for students to examine drought history using multiple parameters. Lastly, sensor deployment and limitations of each data source are described so that students understand both the history of place as well as the process and development of science. Through the use of a place-based curriculum design and interdisciplinary lab exercises, students gain a holistic understanding of a regional watershed.
\end{abstract}

\section{INTRODUCTION}

Student engagement in introductory STEM courses is a strong indicator of subsequent success and retention in higher education (Roberts, 2018). To support non-science majors in STEM classes, faculty should emphasize the applicability and relevance of curriculum and encourage inquiry-based learning (Denson, et al., 2015). Creating inclusive and applied course materials is vital for the achievement of individual students and the university as a whole (Bell, et al., 2009). While there are numerous teaching methods to encourage student participation, place-based education has persisted over two decades as a successful experiential learning strategy (Haskin, 1999; Johnson, 2012).

The goal of this project was to generate placed-based introductory STEM teaching materials incorporating both environmental science and remote sensing concepts. This project examines the Lake Lanier watershed in North Georgia, U.S. The Lake Lanier watershed includes the University of North Georgia Gainesville campus and is the home location for the majority of our students. Examining local watersheds is a common place-based strategy as students bring prior knowledge about the area to the classroom and contribute their past experiences to class projects (Freeman, et al., 2017). Examining the local watershed also allows students to continue making connections between coursework and their lives as they move throughout their day within the study area environment.

This project generated locally focused, interactive remote sensing apps and educational materials. Most course resources were designed for easy modification and reuse. To encourage revision and adoption of course materials by faculty in other locations, we use globally or nationally available datasets and provide Google Earth Engine (GEE) app source code scripts. Recent technological advancements in remote sensing allow for rapid creation of custom web interfaces and apps. Cloud computing and vast data libraries, such as GEE and Sentinel Hub, provide ease of access to massive, global databases. We provide instructions for faculty to adapt course content for local areas. The open-access educational resources are shared internally within the University of North Georgia and are included in the "GIS Lab Collection" website as part of the National Science Foundation Advanced Technological Education Program Applying Geospatial and Engineering Technology Grant (Award \#1700568, http://www.visualecogeo.com/iesa-ate\#/gis-labs/). Lastly, the curriculum uses a modular structural design, with individual exercises provided as distinct units to allow for adoption of the entire curriculum or use of individual exercises.

Placed-based education examines how policy, environment, land use, and history come together to form a unique location. Students in our classes are generally aware of the Lake Lanier watershed but benefit tremendously from formalized exploration of place. The watershed includes the largest consumptive use reservoir for the City of Atlanta, Georgia. In addition, the watershed underwent extreme land use transformation over the past few decades (Lo \& Yang, 2002; Liu \& Yang, 2015). We integrate remote sensing approaches with other scientific practices to encourage cross-validation and comparison of data collection methodologies (Williams, et al., 
2016). The intentionally integrated curriculum design encourages students to understand how aerial, satellite, and field-based sensors function in tandem. Exploration of data collection also emphasizes the scientific method and process of knowledge formation. Course resources include discussion of satellite orbital paths, data sampling procedures using water quality sondes, and field-based real-time data collection using stream-gauge networks.

\section{THEORETICAL FRAMEWORK}

\subsection{Place-Based Education}

This project utilizes place-based education pedagogies. Placemaking "does not require special sensibilities or cultivated skills. It is a common response to common curiosities-what happened here? Who was involved? What was it like? Why should it matter? - and anyone can be a place-maker who has the inclination" (Johnson, 2012). Place-based strategies are successful because students engage with several high-impact educational practices. Rather than study only the physical environment, place-based education includes overlapping processes and the entanglements between nature and society to consider our cultural creation of place (Johnson, 2012). Coursework can incorporate active learning strategies when students physically visit a location for fieldwork activities (Hammond, et al., 2019). Rather than just study the scientific method didactically, place-based education incorporates inquiry, hypothesis testing, and the application of the scientific method as a process (Perkins, et al., 2010). It allows students to recognize the limitations in their understanding, examine knowledge formation, and utilize metacognition to reflect on their own process of learning (Elfer, 2012). A place-based curriculum can be easily customized based on student interests and incorporate service learning to engage with the local community (Sobel, 2005; Corbett \& Legault, 2019).

We utilize remote sensing and environmental science educational methods to explore the local environment (Figure 1). The importance of remote sensing literacy has intensified over time. Satellite and aerial imagery are increasingly ubiquitous but remain conceptually misunderstood (Williams, et al., 2016). Remote sensing is incorporated in interactive interfaces such as Google Earth, mobile phone navigation systems, and surveillance technology for national security, media, and law enforcement. For students to comprehend the power and importance of remote sensing in their daily lives, they should understand how this data is collected and processed.

\subsection{Active Learning}

Experiential learning incorporates "learning from experience or learning by doing. Experiential education first immerses learners in an experience and then encourages reflection about the experience to develop new skills, new attitudes, or new ways of thinking." (Schwartz, 2012). Experiential learning can be achieved in remote sensing through exploration of data and creative overlap of multiple datasets. Rather than following a scripted procedure, students experience surprise by overlaying remote sensing data with other data types. Field-based remote sensing and use of spectrometers in data collection provide wonderful insight into the application of spectral reflectance curves to identify land surface material. Students can also identify land cover using satellite imagery and then physically explore the location for validation. Field-based ground-truthing is a great way for students to validate information and more accurately interpret remotely sensed information in subsequent classes. Lastly, students can contribute to citizen science by using apps to record ground and sky conditions during satellite fly-over. Field experiences help students understand the challenges of consistent data collection.

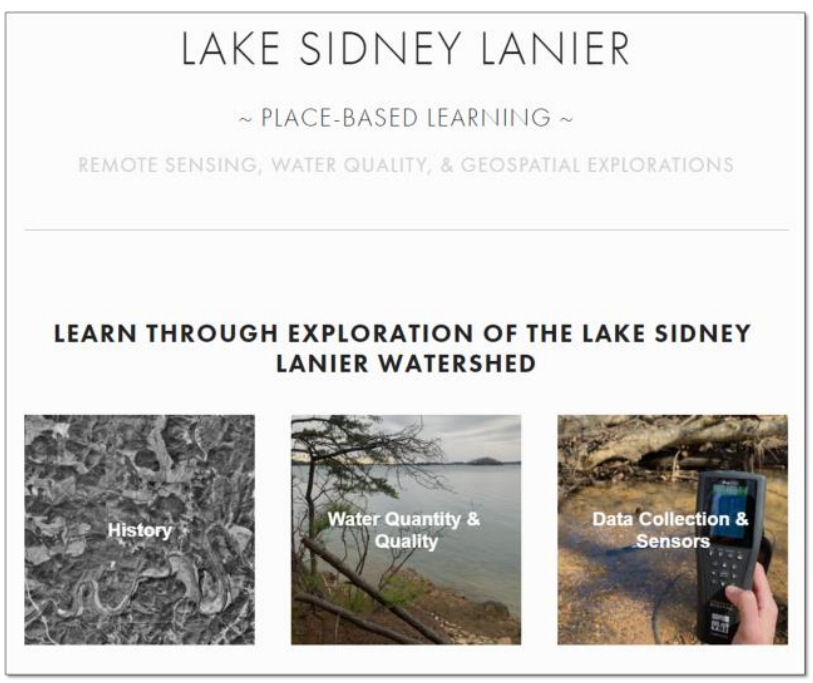

Figure 1. Website with interdisciplinary open education placebased course materials. www.visualecogeo.com/lake-lanier

\subsection{Interdisciplinary Studies}

A guiding principle of this project was interdisciplinary integration of remote sensing and environmental science methodologies in course curriculum. Through exposure to multiple disciplines, introductory-level students gain a more holistic understanding of the study area watershed. Students also acquire familiarity with various specializations and potential career paths. Considering multiple data collection techniques highlights the limitations of each dataset and provides opportunities for cross-validation. Investigating diverse scientific procedures to examine an environmental phenomenon forces students to reflect on science and knowledge formation as a process. Data validation is particularly important in remote sensing because the need to calibrate and validate satellite-derived estimates. Remote sensing specialists rely on collaboration with subject matter experts in different fields of study to interpret land surface processes and confirm results. Interdisciplinary coursework and exposure to multiple methodologies is crucial to teach the importance of collaboration across disciplines.

Place-based coursework highlights how remote sensing is used in tandem with other ways of knowing. In some courses, remote sensing can mistakenly be described as a panacea; a universal solution to replace other scientific methods. Rather than oversell this technology, we encourage comparison of remote sensing data with other data types and direct discussion of advantages and limitations. Comparison of data and scientific procedures promotes understanding of research methods and encourages students to consider how sensors generate data. Remote sensing is a single tool within the broader toolbelt of environmental analysis. 


\subsection{Minimalist Interface Design}

As higher education increasingly relies on computer-based activities, teachers must consider the influence of computer interface design on learning (De Freitas, et al., 2010). Simple graphical user interfaces (GUI) allow students to focus on learning material rather than become distracted by complex computer software. While more research is required, educational research confirms that distraction and high cognitive load negatively affect learning (Baker, et al., 2015). We prioritized creation of individual, extremely simple map applications to support student engagement. Educators may be tempted to provide intricate tools which can accomplish numerous tasks and display a wealth of data. However, it is often more effective to provide focused visualizations that target the specific scientific concepts you want students to learn. Although it may seem counterintuitive, simple and uncluttered data visualizations, maps, and graphs are more powerful communicators than complex toolsets (Knaflic, 2015).

\section{METHODOLOGY}

An open-access website provides a centralized collection of interdisciplinary place-based learning materials for the Lake Lanier watershed (http://www.visualecogeo.com/lake-lanier; Figure 1). Learning resources include lab exercises, interactive web maps, and activities to address a variety of learning goals. The modular course design provides flexibility and allows educators to select individual learning activities based on curriculum requirements (Bodzin, et al., 2014). To encourage reuse and a customizable classroom experience, exercises can be used in isolation or compiled into a larger course design. Learning resources for the Lake Lanier watershed are divided into categories such as: environmental history, water quality \& quantity, and data \& sensors.

\subsection{Environmental History}

For students to understand the creation of "place", historical context is crucial. Within the Lake Lanier watershed, drastic modification of land use and sweeping land cover alteration reflect the region's shifting social and economic history (Liu \& Yang, 2015). Examining environmental change over time allows students to frame subsequent scientific learning within a historical context. Considering past cultures facilitates crosscultural understanding of environmental history and reframes perception of place (Fath \& Beck, 2005).

Students initially investigate native lands using the Native Lands Digital website (https://native-land.ca/). This overview of native territory and indigenous peoples is vital as current land use patterns and dynamics must be interpreted in comparison to pre-colonial environments. We then utilize a custom GEE map application to examine the last seventy years of land cover change. Historic aerial imagery for Hall County, Georgia from 1955 was georeferenced, uploaded as a GEE asset, and incorporated within a simple time slider interface (Figure 2). Imagery from 1955 shows tremendous land cover conversion as Buford Dam was subsequently constructed to flood the Chattahoochee River and create Lake Sidney Lanier reservoir. In the classroom, the historic time slider generated great excitement, prompted immediate awareness of dam formation, and inspired students to learn more. The historic time-slider also helps focus student attention because the interactive website is extremely simple in design.
Students are encouraged to identify landscape patterns using the 1955 aerial imagery. Visual interpretation of imagery creates skills in pattern recognition and awareness of different land use distributions. We ask students to identify cotton terracing and use this to discuss the history of cotton farming, the devastating history of slavery, and the profound social implications that still reverberate in the watershed today. When guiding students to interpret imagery, it is important to connect land use with people. Ask questions to prompt discussion of society and environment today and in the past based on the configurations visible in imagery. What do certain land cover patterns indicate today? What did these land use patterns indicate in the past? Why do some land covers persist and other areas change? How do we value the land and water?

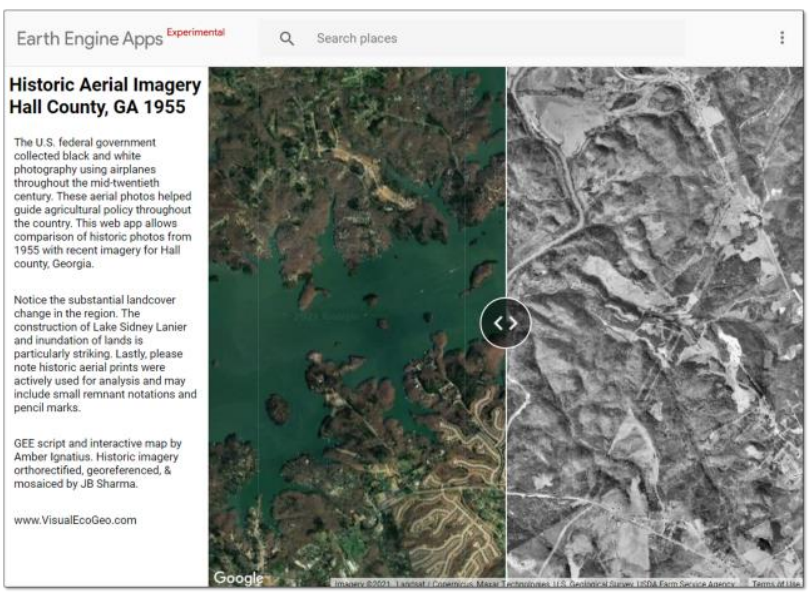

Figure 2. Google Earth Engine map application for historical land cover change examination of the Lake Sidney Lanier watershed.

While remote sensing scientists may intuitively interpret imagery, students require deliberate practice to interpret aerial photos. Photos and videos from the watershed connect remotely sensed imagery with on-the-ground perspectives of the landscape. A U.S. Army Corps of Engineers video showing dam construction provides a real-world viewpoint of dam creation. We also encourage students to interpret current land cover using recent imagery and then physically visit these locations on campus.

Google Earth Timelapse provides more recent land cover change interpretation from 1984-present. The ease of this interface cannot be overstated. The extreme change seen between 1984-present within the local study area is striking. Students are often able to identify the construction of their own neighborhoods, giving the course a direct connection to their lives. One of the benefits of place-based education is that personal connection promotes long-term learning and retention of course concepts. Google Earth Timelapse imagery is global in extent and regularly updated, allowing the interface to grow into the future with the course.

\subsection{Water Quality and Quantity}

Investigation of water quality and quantity is paired with discussion of spectral bands, false color band combinations, and spatial resolution. We begin with an introduction to basic remote sensing concepts supported by a National Ecological Observatory Network explanatory video (NEON, 2015). A custom GEE map application provides comparison of 
reflectance values using several spectral band combinations for the Lake Lanier watershed (Figure 3). Reflectance data identifies suspended sediment in surface waters and shows higher turbidity in the headwaters compared to the deep waters near the dam. These spatial differences help students understand how spectral bands assist with interpretation of land and water properties (Cheung, et al., 2011). Maps showing thermal data allow students to perceive spatial variability of water quality as shallower coastal waters are warmer. Temporal variation is also evident as seasonal variations alter water quality (Ignatius \& Rasmussen, 2016).

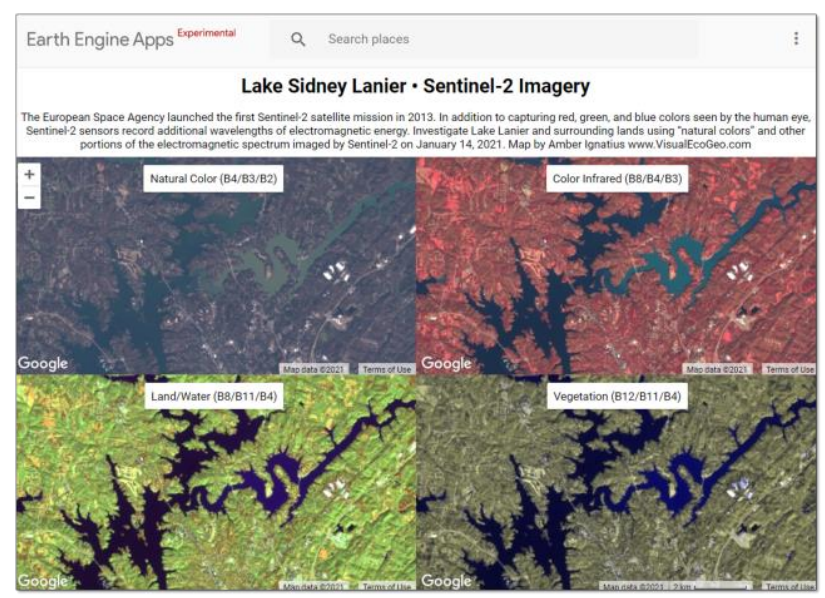

Figure 3. Google Earth Engine map application for Sentinel-2 band combination comparison of Lake Sidney Lanier.

A time slider map application allows for comparison of the Lake Lanier reservoir during drought conditions and full-pool conditions (Figure 4). This is coupled with USGS streamgage real-time flow measurements on the Chattahoochee River. The drought comparison interactive map application shows the exposed shoreline which occurred during extreme drought between 2007-2009. Many students remember this in their own lives and find it quite fascinating to view the drought and low water levels through a historical lens using remotely sensed Landsat data. Drought creates opportunities to discuss Ecology and Geographic concepts such as fragmentation and connectivity. The imagery shows small islands becoming exposed and some islands connecting to the shoreline, providing opportunities to discuss plant and animal migration.

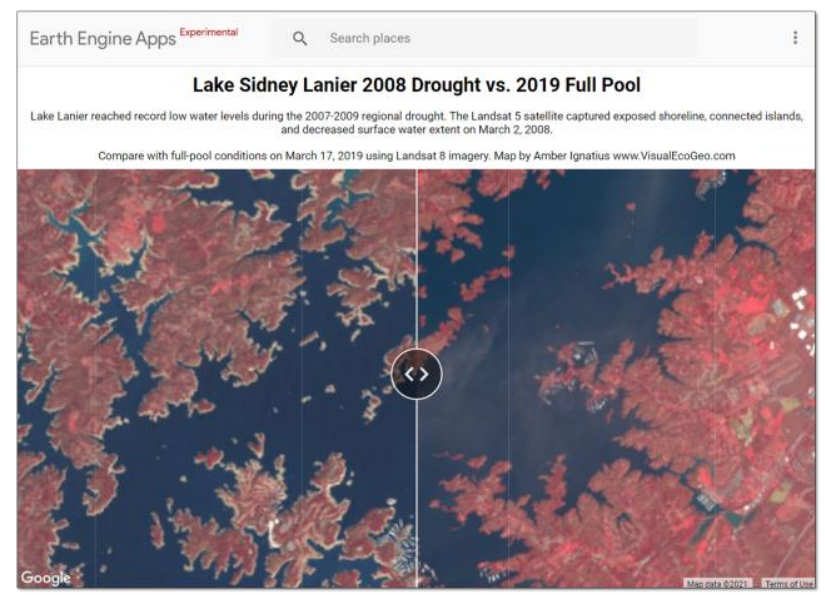

Figure 4. Google Earth Engine map application for Landsat 5 and Landsat 8 drought assessment of Lake Sidney Lanier.

\subsection{Data Collection \& Sensors}

We include a specific module to investigate how different sensors collect information about the watershed. Comparison of multiple data sources provides a more comprehensive understanding of the study area. In addition, information about data collection procedures and sensors demystifies the process of science and allows students to understand the iterative process of observation, data collection, and interpretation. We incorporate multiple learning tools such as videos, web apps, and fact sheets about data, sensors, and collection methods.

Different water quantity methods are presented for comparison. While stream discharge and reservoir surface area both relate to water quantity, the data collection methods utilize quite different methodologies. A USGS stream collects stream discharge measurements using field-based stations and data collection every 15 minutes. In contrast, surface area estimates rely on satellite overpass. The European Space Agency orbital prediction tool demonstrates the frequency of different satellites overpass in the Lake Lanier watershed. Comparison of data collection methodologies gives students an opportunity to think about temporal resolution and cross-validation. Awareness of sensor networks will become more vital over time with increased "internet of things" deployment in the future.

We also use a GEE map application showing raw Sentinel 2 imagery for Lake Lanier. Investigating the available images allows students to understand the scope of the Sentinel archive and consider the importance of cloud cover as a limiting factor. The limitation of cloud cover in passive remote sensing is a significant limitation, especially in humid areas such as the southern U.S. The Sentinel Explorer also shows the date range of the data product, a critical consideration which students often are not able to fully appreciate until they hit a date limitation. The data discussion also features a LiDAR-based point cloud and digital elevation model contour lines using SRTM. This side-by-side comparison invites students to consider how topography of the watershed is modeled and monitored.

It is important for students to conceive of data creation from sensor measurements, to raw data, to actionable information. When soliciting student feedback, we often received questions about how sensors work. Many deep-thinking, hands-on, and inquisitive non-traditional students often ask questions about how scientists get the data. By investigating sensors, students gain a more concrete sense of data as a representation of reality. Collecting data, processing this information, and portraying it on a spreadsheet or map are crucial aspects of Science and investigation into our shared reality.

\section{CONCLUSIONS}

Place-based educational resources provide opportunities for students to explore their local watershed using a combination of custom google earth engine map applications and interdisciplinary environmental data. Learning resources utilize approaches from multiple fields of study and were intentionally designed to seamlessly integrate remote sensing approaches and traditional environmental science methods. Students learn about electromagnetic energy and spectral reflectance through examination of local land cover. In addition, the learning materials require students to contemplate the process of knowledge-formation by considering the limitations and potential applications of different scientific approaches. Future steps include augmenting instructional guidance to support modification of curriculum for re-use in other locations. Lastly, 
additional assessment of teaching strategies and inclusivity of educational resources is required.

\section{ACKNOWLEDGEMENTS}

This work is supported by the University of North Georgia Presidential Semester Incentive Award and the National Science Foundation Advanced Technological Education Program Award \#1700568. Any opinions, findings, and conclusions or recommendations expressed in this material are those of the author(s) and do not necessarily reflect the views of the University of North Georgia or National Science Foundation.

\section{COMPETING INTERESTS STATEMENT}

The authors have no competing interests to declare.

\section{REFERENCES}

Baker, T., Battersby, S., Bednarz, S., Bodzin, A., Kolvoord, R., Moore, S., Sinton, D., \& Uttal, D., 2015., A research agenda for geospatial technologies and learning. Journal of Geography, 114(3), 118-130. doi: 10.1080/00221341.2014.950684

Bell, P., Lewenstein, B., Shouse, A.W., \& Feder, M.A., 2009. Learning Science in Informal Environments: People, Places, and Pursuits. National Research Council. Washington: DC: The National Academies Press.

Bodzin, A., Fu, Q., Kulo, V., \& Peffer, T. 2014., Examining the enactment of a geospatial curriculum design approach on students' geospatial thinking and reasoning. Journal of Science Education and Technology, 23, 562-574. doi: 10.1007/s10956014-9488-6

Cheung, Y., Pang, M., Lin, H., Lee, \& C.K.J., 2011. Enable Spatial Thinking Using GIS and Satellite Remote Sensing - A Teacher-Friendly Approach, Procedia - Social and Behavioral Sciences, Volume 21, Pages 130-138, ISSN 1877-0428, https://doi.org/10.1016/j.sbspro.2011.07.014.

Corbett, J., \& Legault, G., 2019. Neogeography: Rethinking Participatory Mapping and Place-Based Learning in the Age of the Geoweb. 10.1007/978-3-030-06058-9_8. In book: Water Governance: Challenges and Prospects pp. 123-143.

De Freitas, S., Rebolledo-Mendez, G., Liarokapis, F., Magoulas, G., \& Poulovassilis, A., 2010. Learning as immersive experiences: Using the four dimensional framework for designing and evaluating immersive learning experiences in a virtual world. British Journal of Educational Technology, 41(1), 69-85.

Denson, C.D., Hailey, C., Stallworth, C.A., \& Householder, D.L., 2015. Benefits of informal learning environments: a focused examination of STEM-based program environments. Journal of STEM Education: Innovations and Research, 16(1), 11 .

Elfer, C. 2012. Place-Based Education in Georgia: Imagining the Possibilities for Local Study in the Contemporary Social Studies Classroom. Georgia Social Studies Journal. 2. 46-51.
Fath, B., \& Beck, M.B., 2005. Elucidating public perceptions of environmental behavior: A case study of Lake Lanier. Environmental Modelling \& Software. 20. 485-498. 10.1016/j.envsoft.2004.02.007.

Freeman, S., Eddy, S.L., McDonough, M., Smith, M.K., Okoroafor, N., Jordt, H., \& Wenderoth, M.P., 2014. Active learning increases student performance in science, engineering, and mathematics. Proceedings of the National Academy of Sciences 111(23): 8410-8415.

Hammond, T., Bodzin, A., Popejoy, K., Anastasio, D., Holland, B., \& Sahagian, D., 2019. Shoulder to Shoulder: Teacher Professional Development and Curriculum Design and Development for Geospatial Technology Integration With Science and Social Studies Teachers. Contemporary Issues in Technology and Teacher Education, 19(2), pp. 279-301.

Haskin, J., 1999. Place-Based Learning: The Technology Frontier in Environmental Education. Educational Technology, 39(6), 59-63.

Ignatius, A. \& Rasmussen, T. 2016. Small reservoir effects on headwater water quality in the rural-urban fringe, Georgia Piedmont, USA. Journal of Hydrology: Regional Studies. 8. 10.1016/j.ejrh.2016.08.005.

Johnson, J.T., 2012. Place-based learning and knowing: Critical pedagogies grounded in Indigeneity. Geojournal. 75. 10.1007/s10708-010-9379-1.

Knaflic, C.N. 2015., Storytelling With Data: A Data Visualization Guide for Business Professionals. Hoboken, New Jersey: John Wiley \& Sons, Inc.

Liu, T. \& Yang, X., 2015. Monitoring land changes in an urban area using satellite imagery, GIS and landscape metrics. Applied Geography. 56. 42-54. 10.1016/j.apgeog.2014.10.002.

Lo, C.P., \& Yang, X., 2002. Drivers of land-use/land-cover changes and dynamic modeling for the Atlanta, Georgia Metropolitan Area. Photogrammetric Engineering and Remote Sensing. 68. 1073-1082.

NEON (National Ecological Observatory Network), 2015. NEON: Mapping the Invisible: Introduction to Spectral Remote Sensing [Video]. YouTube: https://www.youtube.com/watch?v=3iaFzafWJQE

Perkins, N., Hazelton, E., Erickson, J., \& Allan, W., 2010. Place-based education and geographic information systems: Enhancing the spatial awareness of middle school students in Maine. Journal of Geography, 109, 213-218.

Roberts, T., Jackson, C., Mohr-Schroeder, M., Bush, S., Maiorca, C., Cavalcanti, M., Schroeder, D. Delaney, A., Putnam, L., \& Cremeans, C., 2018. Students' perceptions of STEM learning after participating in a summer informal learning experience. International Journal of STEM Education, 5(35), pp. 1-14.

Schwartz, M. 2012. Best Practices in Experiential Learning. Ryerson University The Learning and Teaching Office. https://www.mcgill.ca/eln/files/eln/doc_ryerson_bestpracticesry erson.pdf 
Sobel, D., 2005. Place-based education: Connecting classroom and communities. Great Barrington, MA: The Orion Society.

Williams, R., Tooth, S., \& Gibson, M., 2016. The sky is the limit: reconstructing physical geography from an aerial perspective. Journal of Geography in Higher Education. 41. 113. 10.1080/03098265.2016.1241986. 